\section{Restricted Water Availability During Lettuce Seed Production Decreases Seed Yield per Plant but Increases Seed Size and Water Productivity}

\author{
Samuel Contreras ${ }^{2}$ \\ Departamento de Ciencias Vegetales, Pontificia Universidad Católica de \\ Chile, Av Vic Mackenna 4860, Casilla 306-22, Santiago, Chile
}

\author{
Mark A. Bennett \\ Department of Horticulture and Crop Science, Ohio State University, \\ Columbus, OH 43210-1086
}

\section{David Tay ${ }^{1}$ \\ Ornamental Plant Germplasm Center, Ohio State University, Columbus, OH 43210-1086}

Additional index words. Lactuca sativa, germinability, photodormancy, seed storability, seed development, harvest index

\begin{abstract}
Lettuce (Lactuca sativa) is an important vegetable crop worldwide, and its seed is commercially produced mainly under irrigation in arid and semiarid regions. The objective of this study was to determine how water availability during seed development affects lettuce seed productivity and quality. Three experiments were performed in the greenhouse and growth chambers using lettuce (cv. Tango) cultivated in pots. When watering volume was restricted (dry treatment) from bolting to seed harvest to $54 \%$ of the well-watered control (wet treatment), plants were shorter, had reduced dry weight, and produced fewer and heavier seeds. Water productivity (seed yield/watering volume) was nearly $50 \%$ higher in the dry treatment. Seeds from the dry treatment had a modest improvement in seed vigor (assessed by seedling growth) and decreased germinability (higher sensitivity to exogenous abscisic acid and water potential) compared with the wet treatment. In another experiment, water stress was applied abruptly to well-hydrated lettuce plants with developing seeds. Seeds that were at one-third and two-thirds of physiological maturity when water was withheld had lower germinability and greater storability than seeds with no water restriction. These results provide information that may be used for improvement of irrigation practices for lettuce seed production.
\end{abstract}

The availability of water to the mother plant during seed production is important because it affects seed yield and quality of many species. In general, most of the research on water requirements of different crops has focused on optimizing yield of commodity products and only rarely considered seed yield or quality parameters (George, 1999). Optimal water management for seed production may be different from best management

Received for publication 16 Nov. 2007. Accepted for publication 6 Jan. 2008

Salaries and research support were provided by state and federal funds appropriated to The Ohio State University, Ohio Agricultural Research and Development Center as well as a Fulbright Scholarship to S. Contreras.

We thank Hank Hill from Seed Dynamics Inc. for providing lettuce seeds and technical advice used in this study and Miller McDonald and Dave Barker for critical review of the manuscript (MS07-23).

${ }^{1}$ Current address: International Potato Center, Apartado 1558, Lima 12, Peru.

${ }^{2}$ To whom reprint requests should be addressed; e-mail scontree@uc.cl practices for crop production, especially in species for which the final products are not grains (e.g., many vegetables and forages).

Effects of water stress on seed yield depend on the crop and will vary depending on the intensity, duration, and timing of the water deficit (Izzeldin et al., 1980). In general, water stress before and during flowering has been observed to affect seed yield by reducing the number of seeds produced per plant (Bartels and Caesar, 1987; Champolivier and Merrien, 1996; Oliva et al., 1994; Žebrauskiene et al., 2005), whereas individual seed weight has been affected by water deficit after flowering (Castañeda et al., 2006; Champolivier and Merrien, 1996; Fougereux et al., 1997; Ludlow et al., 1990; Ramamoorthy and Basu, 1996). However, there are cases in which moderate water deficits have increased seed yield or seed size. For instance, Shock et al. (2007) reported that moderate deficit irrigation from flowering to seed maturity improved yield and individual weight of alfalfa (Medicago sativa L.) seeds. Santos et al. (2006) observed that seeds of wild bushbean (Macroptilium lathyroides L.) were heavier when produced under restricted water availability $(60 \%$ to $70 \%$ soil field capacity). Less research has examined the effects of water stress on other aspects of seed quality such as germination, germinability, and storability. In general, the consensus is that water deficiency during seed development reduces dormancy and improves germination of wild species (Fenner, 1991; Gutterman, 2000; Hilhorst and Toorop, 1997). Water deficit had no effect on seed germinability and vigor of onion (Allium cepa L.) (Žebrauskienè et al., 2005), peanut (Arachis hypogaea L.) (Ramamoorthy and Basu, 1996), and maize (Zea mays L.) and sorghum [Sorghum bicolor (L.) Moench.] (Ghassemi-Golezani et al., 1997). Zhao et al. (1993) observed that seeds from water-stressed cotton (Gossypium hirsutum L.) plants had faster germination and higher vigor. Ramamoorthy and Basu (1996) and Sinniah et al. (1998) reported that water deficit during seed production improved storability of peanut and rapid-cycling brassica [Brassica campestris (rapa) L.] seeds, respectively.

Lettuce (Lactuca sativa L.) is one of the most important vegetables in the world. In the United States, between 2001 and 2006, lettuce was cultivated on over 121,000 ha per year with an annual crop value of $\approx 2$ billion dollars, which makes it the most valuable fresh vegetable in the country (U.S. Department of Agriculture, 2007). Lettuce seed quality is important because it affects establishment of the crop along with final yield and quality (Smith et al., 1973b; Wurr and Fellows, 1985). Working with pot-grown lettuce plants in the greenhouse, Soffer and Smith (1974) observed that withholding water and nutrients during the last half ( 20 to $25 \mathrm{~d}$ ) of the seed production period did not affect seed yield per plant, seed weight distribution, or seedling vigor (measured as seedling root length). Izzeldin et al. (1980) studied the effects of water stress on lettuce seed yield and quality by applying three levels of soil moisture deficit $(-0.03,-$ 0.08 , and $-0.5 \mathrm{MPa}$ ) at different growth stages of plants grown in a greenhouse. These authors reported that lettuce plants under moderate water deficit produced the highest seed yields; however, the highest quality (size and vigor measured as seedling radicle elongation) occurred for seeds produced under severe water stress treatments.

Because lettuce seeds are mainly produced in arid and semiarid conditions, understanding the effects that restricting water has on seed yield and quality is important to optimize the use of irrigation water. The objective of this study was to determine how water availability during seed development affects lettuce seed production, especially seed yield and quality.

\section{Materials and Methods}

Expt. 1

'Tango' (green leaf type) lettuce plants were produced in the greenhouse in $1.75-\mathrm{L}$ 
plastic pots filled with a soilless growth medium (Metromix 360; Scotts, Marysville, $\mathrm{OH})$. Plants were irrigated daily and each pot was fertilized weekly with $50 \mathrm{~mL}$ of a solution containing $35 \mathrm{mg}$ nitrogen, $15 \mathrm{mg}$ phosphorus, and $29 \mathrm{mg}$ potassium (Peters Professional; Scotts). At bolting (10 June), plants were randomly assigned to one of three treatments: 1) wet, 2) dry, and 3) very dry. Daily watering volume for plants in the wet treatment was between 300 and $450 \mathrm{~mL}$, depending on daily temperatures, whereas plants from the dry and very dry treatment received 200 and $100 \mathrm{~mL}$ of water per day, respectively. Plants were grouped in four replications or blocks (randomized complete block design). Each replication consisted of three plants, which were evaluated together.

Average air temperature in the greenhouse from early flowering (25 June) up to the last harvest ( $31 \mathrm{July}$ ) was $22.4{ }^{\circ} \mathrm{C}$ with maximums that ranged between 29.4 and $21.6^{\circ} \mathrm{C}$ and averaged $25.0^{\circ} \mathrm{C}$ and minimums that ranged from 23.1 to $18.1{ }^{\circ} \mathrm{C}$ and averaged $20.0^{\circ} \mathrm{C}$. Plant evapotranspiration (ET) was measured on 2 July $\left(24.2^{\circ} \mathrm{C}\right.$ average temperature) as the plant (including pot and growth medium) weight lost after irrigation in a 24-h period. Plant transpiration was measured similarly, but evaporation was suppressed by covering the soilless mix surface of the pot with a layer of aluminum foil. For each treatment, ET and transpiration measurements were performed using one plant per replication. Volumetric soil water content was measured on each pot on 30 June and 3 July by using a time-domain reflectometer (Soilmoisture Equipment Corp., Santa Barbara, CA).

Several lettuce seed harvests were conducted manually between 16 and 31 July, cutting only fully mature flower heads (dry with exposed seeds) with scissors. Once harvested and cleaned, seeds were desiccated to $8.4 \%$ water content using anhydrous $\mathrm{CaSO}_{4}$ in a closed container and then stored inside hermetic plastic bags at $10{ }^{\circ} \mathrm{C}$ until evaluation ( 1 to 2 months after harvest). Seed weight and water content were calculated using 100 seeds per replication and drying the seeds in an oven at $103{ }^{\circ} \mathrm{C}$ for $48 \mathrm{~h}$. After the last harvest, plant dry weight (excluding roots) was determined by drying the plants for $96 \mathrm{~h}$ at $60^{\circ} \mathrm{C}$.

Seed evaluation. The standard germination test was conducted with 50 seeds from each replication. Seeds were planted over two layers of blotter paper (Anchor Paper Co., St. Paul, MN), saturated in distilled water and placed in transparent plastic boxes $(11 \times 11 \times$ $4 \mathrm{~cm})$. These boxes were placed in a germination chamber at $20^{\circ} \mathrm{C}$ and constant light. After 4 and $7 \mathrm{~d}$, only normal seedlings were counted as germinated (International Seed Testing Association, 1999).

Other germination tests were conducted using 50 seeds per replication planted over two layers of blotters saturated in $10 \mathrm{~mL}$ distilled water or $10 \mathrm{~mL}$ of solution containing various concentrations of $( \pm)$ abscisic acid (ABA; 12.5, 25, 50, and $100 \mu \mathrm{M}$;
Sigma-Aldrich, St. Louis, MO) or polyethylene glycol (PEG 8000; Sigma-Aldrich) and placed in petri dishes $(9 \mathrm{~cm}$ diameter $)$. The PEG concentrations used were calculated to obtain water potentials of $-0.15,-0.30$, -0.45 , and - 0.60 MPa (Michel, 1983). Germination tests at different $\mathrm{ABA}$ and PEG concentrations were performed at $20{ }^{\circ} \mathrm{C}$ and constant light with counts of germinated seeds (radicle emergence) at 2, 4, 6, 8, 10, and $12 \mathrm{~d}$. The germination index (GI) was calculated according to the following equation (adapted from Maguire, 1962):

$\mathrm{GI}=($ ratio of germinated seeds day 2$) / 2+\ldots$ $+($ ratio of germinated seeds day " $\mathrm{X}$ ") $) /$ " $\mathrm{X}$ ", $+\ldots+($ ratio of germinated seeds day 12$) / 12$.

Germination at $30{ }^{\circ} \mathrm{C}$-light and $20{ }^{\circ} \mathrm{C}-$ dark was evaluated at 7 and $4 \mathrm{~d}$ after sowing, respectively.

Vigor index and average radicle length measurements were determined on 50 seeds per replication using the Seedling Vigor Image System (SVIS, Ohio State University, Columbus, $\mathrm{OH}$ ) according to methodology described by Sako et al. (2001).

The data were analyzed as a randomized complete block design using the analysis of variance procedure of SAS (SAS Institute, Cary, NC). Before the analysis, germination percentages and GI values were transformed to the arcsin of the square root of the fraction value. When significant differences existed $(P<0.05)$, the least significant difference $(\alpha$ $=0.05)$ was calculated to establish differences among treatments.

\section{Expt. 2}

Vegetative stage lettuce plants were cultivated in the greenhouse as described for Expt. 1. At bolting (9 July), plants were assigned randomly to one of two treatments: 1) wet or 2) dry. From bolting to flower initiation, plants in the wet and dry treatments were irrigated with 300 and $150 \mathrm{~mL}$ of water, respectively. Plants were grouped in four blocks or replications, each with six plants per treatment. After flower initiation, two plants per replication (including pot and growth medium) were weighed each morning before watering. Evapotranspiration was calculated as the plant weight difference immediately after irrigation and before irrigation the next day. In this way, the watering volume for each treatment was determined daily as equivalent to the ET of the previous day. On average, from flowering (29 July) to the final harvest (1 Sept.), the watering volume of the dry treatment was $54 \%$ of the volume for the wet treatment.

Approximately 10 flower heads per plant were labeled with a colored string on the day of flowering (10 Aug.). Six flower heads per replication were sampled at $4,6,8,10,12$, and $14 \mathrm{~d}$ after flowering (DAF), and fresh and dry weight of seeds were determined.

Three harvests were conducted manually, cutting with scissors only mature flower heads, on 12 and 23 Aug. and 1 Sept. In each harvest, the number of seeds per flower head was calculated from a sample of 20 heads per replication. Desiccation, storage, and weight evaluation of the seeds was accomplished as described in Expt. 1. After the last harvest, plant height and dry weight (excluding roots) were determined. For each replication, the harvest index was calculated as the fraction between the dry weight of seeds harvested and dry weight of the plants (including seeds).

Seed evaluation. Only seeds from the second harvest (23 Aug.) were used for germination and germinability assessment. Seed evaluation and data analysis were performed according to methodology described in Expt. 1. For the accelerated aging (AA) test, lettuce seeds were aged at $41{ }^{\circ} \mathrm{C}$ and $\approx 100 \%$ relative humidity $(\mathrm{RH})$ for $72 \mathrm{~h}$ and then germinated following the standard germination protocol; normal seedlings were evaluated $11 \mathrm{~d}$ after planting.

\section{Expt. 3}

Twelve lettuce plants were cultivated in the greenhouse as previously described and moved to a growth chamber when bolting occurred. Air temperature in the chamber was 25 and $15{ }^{\circ} \mathrm{C}$ for day $(12 \mathrm{~h}$, fluorescent light, $\approx 310 \mu \mathrm{mol} \cdot \mathrm{m}^{-2} \cdot \mathrm{s}^{-1}$ ) and night, respectively. Each plant was provided $200 \mathrm{~mL}$ water daily until the treatments started. Approximately $10 \mathrm{~d}$ after flower initiation, $\approx 35$ flower heads per plant were labeled with a colored string on the day of flowering. Four plants were randomly assigned to one of three treatments: 1) no water restriction $(200 \mathrm{~mL}$ water per plant), 2) no watering from 8 DAF (last watering $7 \mathrm{DAF}$ with $100 \mathrm{~mL}$ water), and 3) no watering from 4 DAF (last watering 3 DAF with $100 \mathrm{~mL}$ water). For the control treatment, seed weight accumulation was determined by sampling flower heads at different times after flowering as described for Expt. 2. For each treatment, only labeled flower heads were harvested 27 DAF, when flower heads were dry and open and the seeds had less than $8 \%$ water content. Seeds were cleaned and placed in paper envelopes at $4{ }^{\circ} \mathrm{C}$ and $25 \% \mathrm{RH}$ until evaluation.

Seed evaluation. Seed dry weight and germination data were collected using four subsamples of 50 seeds per treatment. All germination tests were performed as previously described. Normal seedling germination was evaluated $7 \mathrm{~d}$ after planting. Dark germination was evaluated $4 \mathrm{~d}$ after planting. All other germination evaluations were conducted daily until $7 \mathrm{~d}$ after planting. The AA test was performed as described in Expt. 2 . Data are presented as the average and SE values from the four subsamples of 50 seeds each.

\section{Results}

Expt. 1. Water available to the lettuce plants differed for the treatments used with volumetric soil water content for the wet treatment being more than twice greater than that of the dry and very dry treatments (Fig. 1A). For the three treatments, only small 
differences between ET and transpiration volumes were noted (Fig. 1B), which could be the result of the basal leaves of the lettuce plants covering most of the upper surface of the pots and poor water transmission to evaporate from the surface of the medium, thereby reducing the direct water evaporation from the soilless mix. Water ET from pots of each treatment was likely related to the respective daily watering volume; i.e., for the dry and very dry treatments, the values were $\approx 200$ and $100 \mathrm{~mL}$ per day, respectively (Fig. 1B).

Plant dry weight at the end of seed harvest was significantly reduced by the lower watering treatment and was directly related to the watering volume of each treatment (Table 1). However, individual seed dry weight was inversely related with the watering volume and was significantly higher in seeds from the very dry treatment followed by the dry and wet treatments (Table 1). Despite the differences in weight, no significant differences in seed germinability were observed among the treatments, regardless of the temperature or light condition (Table 1). The vigor index and seedling radicle length values from the SVIS analysis tended to increase with decreasing watering volumes during seed production; however, the differences were only significant for radicle length (Table 1). When seed germination was evaluated at different ABA concentrations (Fig. 2A) or water potentials (Fig. 2B), seeds from the wet and dry treatments responded similarly, whereas seeds from the very dry treatment tended to have lower germination percentage and rate (expressed as GI).

Expt. 2. The application of treatments varied slightly from Expt. 1. Because of variation in daily ET associated with the greenhouse temperature, the watering volume of each treatment was determined daily according to the evapotranspiration of the previous day (Fig. 3). The average daily ET and watering volumes for lettuce plants from the dry treatment were $58 \%$ and $54 \%$, respectively, of the values for the wet treatment.

Rates of development and desiccation for lettuce seeds from both treatments were similar (Fig. 4). Seed physiological maturity (defined as the moment of maximum seed dry weight accumulation), determined by an iterative regression analysis procedure (PietaFilho and Ellis, 1991), occurred 10.8 \pm 0.6 and $10.8 \pm 0.3$ DAF for plants from the wet and dry treatments, respectively; however, individual seeds from the dry treatment were $20 \%$ heavier $(P<0.01)$ than seeds from the wet treatment (Fig. 4; Table 2). Plants from the dry treatment were more compact with height and dry weight significantly lower than for the wet treatment (Table 2). Plants from the wet treatment produced more seeds per plant than plants from the dry treatment (Table 2), $47 \%$ more on a number basis $(P=0.01)$ and $23 \%$ more on a dry weight basis $(P=0.05)$. The number of seeds per flower heads in plants from the wet treatment was $10 \%$ higher $(P=0.05)$ than for plants from the dry treatment (Table 2). Despite these differences, the harvest index
A

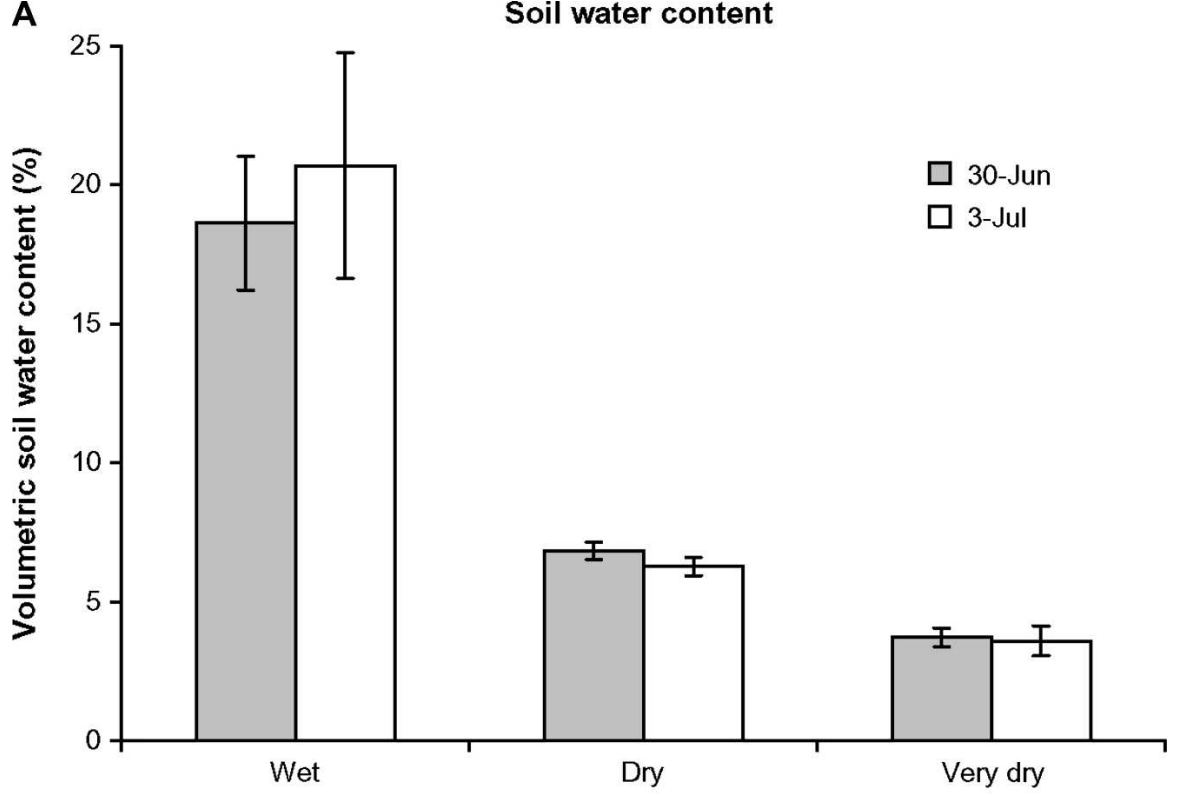

B Plant Evapotranspiration (ET) and Transpiration (T)

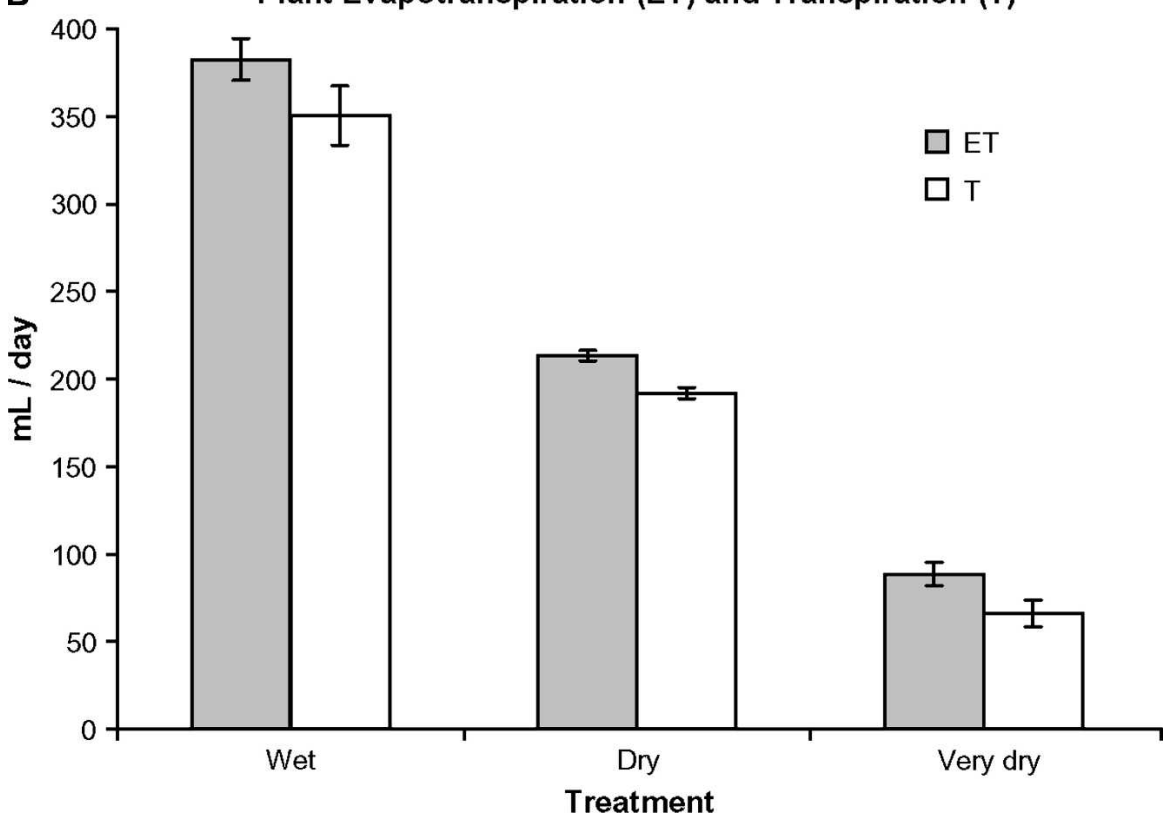

Fig. 1. (A) Soil water content (volume of water/volume of soil) for wet, dry, and very dry irrigation treatments (Expt. 1) on 30 June and 3 July. (B) Lettuce plant evapotranspiration (ET) and transpiration (T) calculated for each treatment from 2 July to 3 July. Data are means \pm SE of four replications.

Table 1. Parameters of growth and seed quality from lettuce plants grown under three daily watering treatments: wet (300 to $450 \mathrm{~mL}$ per plant), dry (200 mL per plant), and very dry (100 $\mathrm{mL}$ per plant) (Expt. 1).

\begin{tabular}{|c|c|c|c|c|c|}
\hline \multirow[b]{2}{*}{ Parameter } & \multicolumn{3}{|c|}{ Treatment } & \multirow[b]{2}{*}{$P$ value $^{\mathrm{z}}$} & \multirow[b]{2}{*}{$\operatorname{LSD}^{\mathrm{y}}(\alpha=0.05)$} \\
\hline & $\overline{\text { Wet }}$ & Dry & Very dry & & \\
\hline$\overline{\text { Plant dry weight (g/plant) }}$ & 23.4 & 13.7 & 7.3 & $<0.01$ & 2.0 \\
\hline Seed dry weight $(\mathrm{mg} / \mathrm{seed})$ & 0.71 & 0.83 & 1.02 & $<0.01$ & 0.05 \\
\hline Normal seedlings at $20^{\circ} \mathrm{C}$-light $(\%)$ & 99 & 99 & 100 & 0.13 & \\
\hline Germination at $20^{\circ} \mathrm{C}$-light $(\%)$ & 100 & 100 & 100 & - & \\
\hline Germination at $25^{\circ} \mathrm{C}$-light $(\%)$ & 100 & 100 & 100 & - & \\
\hline Germination at $30{ }^{\circ} \mathrm{C}$-light $(\%)$ & 95 & 99 & 99 & 0.21 & \\
\hline Germination at $20^{\circ} \mathrm{C}$-dark $(\%)$ & 6 & 16 & 16 & 0.43 & \\
\hline Vigor index ${ }^{x}$ & 515 & 565 & 598 & 0.16 & \\
\hline Radicle length (pixels/seedling) ${ }^{\mathrm{x}}$ & 214 & 216 & 227 & 0.01 & 8.4 \\
\hline
\end{tabular}

${ }^{\mathrm{z} P}$ value from analysis of variance.

${ }^{\mathrm{y}}$ Least significant difference.

${ }^{\mathrm{x}}$ Values from SVIS (Seedling Vigor Image System). 

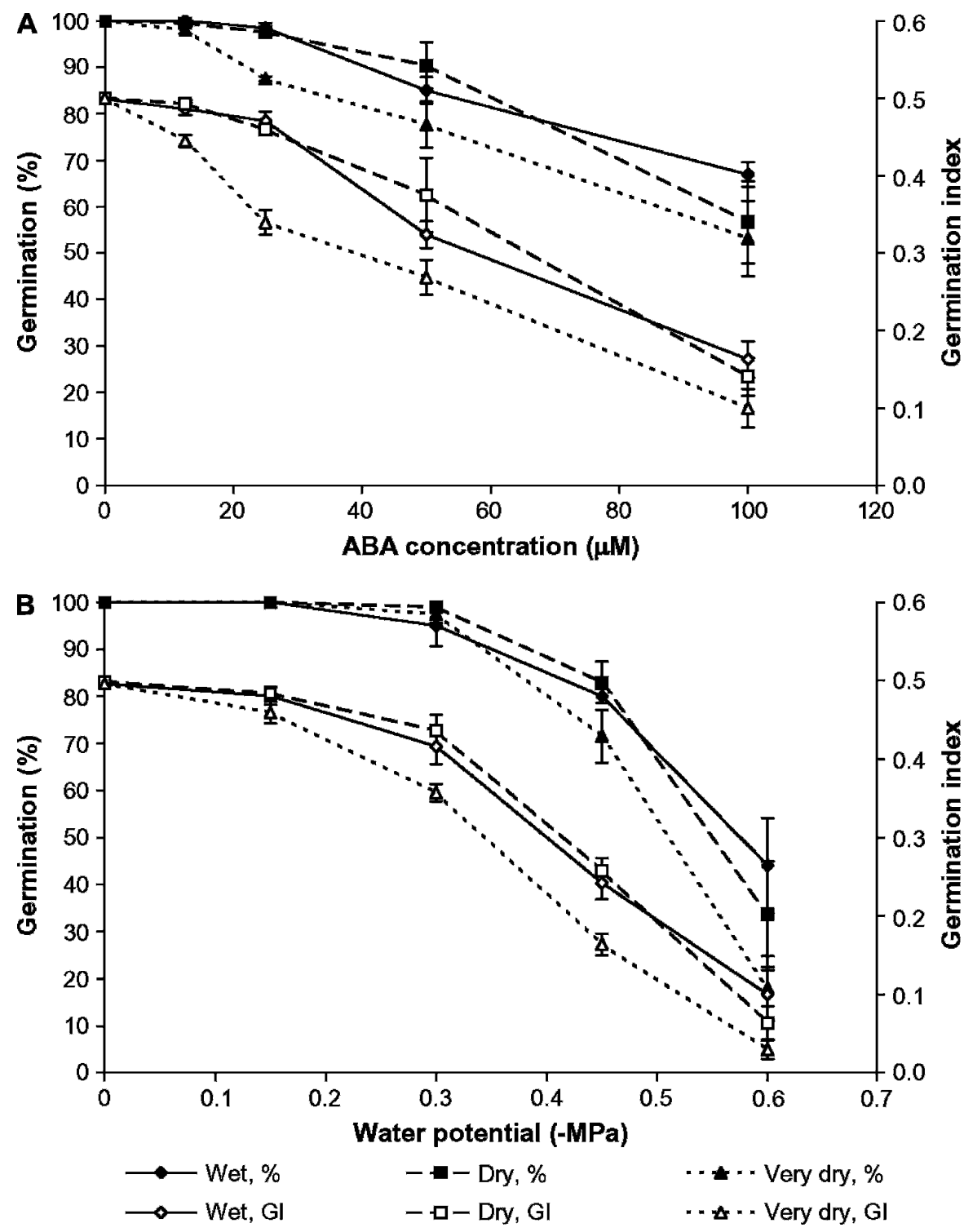

Fig. 2. Germination percentage (\%) and germination index (GI) of lettuce seeds from wet (diamond), dry (square), and very dry (triangle) irrigation treatments (Expt. 1) at five abscisic acid (ABA) concentrations (A) and five water potentials (B). Data are means \pm SE of four replications of 50 seeds each. was similar $(P=0.47)$ for plants from both treatments (Table 2). The water productivity (seed yield per unit of water used; Oweis and Hachum, 2006) was 50\% higher $(P=0.01)$ for plants from the dry treatment (Table 2). As observed in Expt. 1, seed germinability was similar for both treatments despite differences in seed size (Table 2). The vigor index and radicle length were higher for seedlings from the dry treatment seed; however, these differences were not significant (Table 2). Germination percentages and rates from both treatments were affected by exogenous ABA (Fig. 5A) and reduced water potentials (Fig. 5B), similar to what was observed in Expt. 1 (Fig. 2). Germination of seeds from the wet treatment tended to be less affected by exogenous ABA than seeds from the dry treatment (Fig. 5A). At reduced water potentials, reductions in GIs were similar for seeds from both treatments, and little but consistent differences in seed germination percentage favored seeds from the wet treatment (Fig. 5B).

Expt. 3. Lettuce seeds produced by plants under water stress tended to be heavier than seeds from plants without water restriction (Table 3). Percentage of normal seedlings at $20{ }^{\circ} \mathrm{C}$ was higher for seeds from plants without water restriction, although the total germination (percentage and rate) at this temperature (light or dark) was similar for seed from the three treatments. Seed produced without water restriction performed better when germinated at $30{ }^{\circ} \mathrm{C}$ (light or dark) and with exogenous ABA; however, at a $-0.4 \mathrm{MPa}$ water potential, this seed had a lower percentage of germination (Table 3 ). After $72 \mathrm{~h}$ of accelerated aging at $41{ }^{\circ} \mathrm{C}$ and $\approx 100 \% \mathrm{RH}$, seeds from plants under water stress, especially the no watering from $8 \mathrm{DAF}$ treatment, performed better.

\section{Discussion}

In Expts. 1 and 2, the watering treatments were initiated at bolting, and reductions in

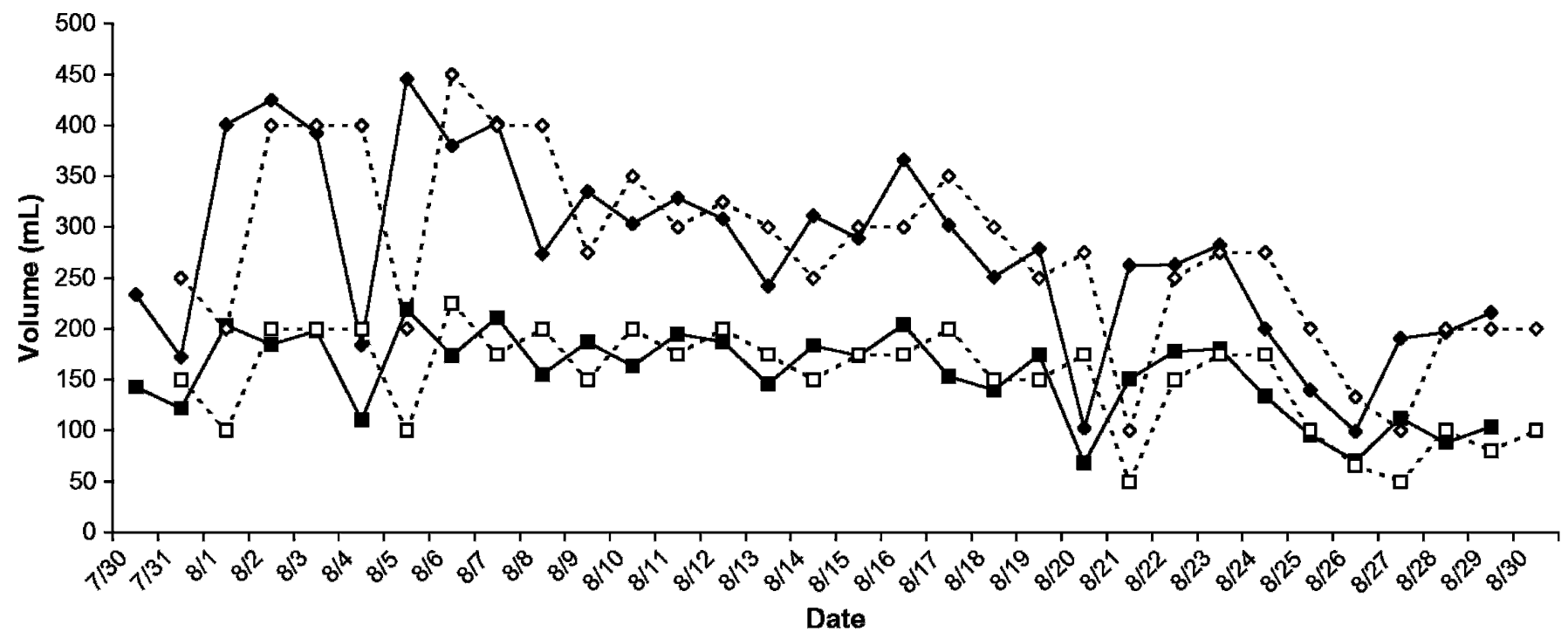

Fig. 3. Daily evapotranspiration (solid line) and watering (broken line) volumes for lettuce plants from wet (diamonds) and dry (squares) irrigation treatments from early flowering to last seed harvest (Expt. 2). 


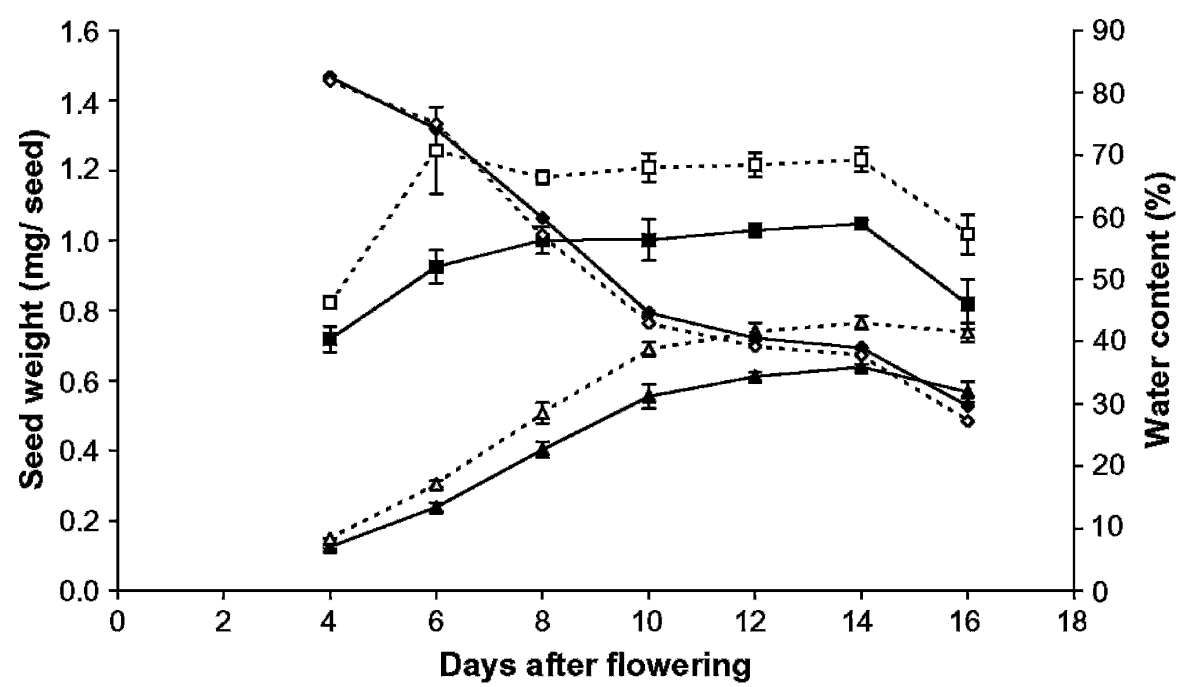

Fig. 4. Fresh weight (squares), dry weight (triangles), and water content (diamonds) of individual lettuce seeds from wet (solid line) and dry (broken line) irrigation treatments during seed development from 4 to $16 \mathrm{~d}$ after flowering (Expt. 2). Data are means \pm SE calculated from four replications (seeds from six flower heads were evaluated in each replication).

Table 2. Parameters of growth, seed yield, and seed quality from lettuce plants grown under different treatments of water availability: wet (daily watering volume equivalent to evapotranspiration volume) and dry (watering volume $\approx 54 \%$ of wet treatment) (Expt. 2).

\begin{tabular}{|c|c|c|c|}
\hline \multirow[b]{2}{*}{ Parameter } & \multicolumn{2}{|c|}{ Treatment } & \multirow[b]{2}{*}{$P$ value } \\
\hline & $\overline{\text { Wet }}$ & Dry & \\
\hline \multicolumn{4}{|l|}{ Growth } \\
\hline Plant height (cm) & 121.0 & 110.0 & 0.02 \\
\hline Plant dry weight (g/plant) & 30.8 & 23.5 & 0.01 \\
\hline \multicolumn{4}{|l|}{ Seed yield } \\
\hline Seeds per flower head & 19.4 & 17.7 & 0.05 \\
\hline Estimated number of seeds per plant & 8,211 & 5,587 & 0.01 \\
\hline Seed dry weight $(\mathrm{mg} /$ seed $)$ & 0.64 & 0.77 & $<0.01$ \\
\hline Seeds per plant (g dry weight/plant) & 5.27 & 4.29 & 0.05 \\
\hline Harvest index ${ }^{y}$ & 0.17 & 0.18 & 0.47 \\
\hline Water productivity $(\mathrm{g} / \mathrm{Lt})^{\mathrm{x}}$ & 0.61 & 0.92 & 0.01 \\
\hline \multicolumn{4}{|l|}{ Seed germination and vigor } \\
\hline At $20^{\circ} \mathrm{C}$-light $(\%)$ & 100 & 100 & 0.39 \\
\hline At $25^{\circ} \mathrm{C}$-light $(\%)$ & 99 & 100 & 0.39 \\
\hline At $30^{\circ} \mathrm{C}$-light $(\%)$ & 99 & 98 & 0.66 \\
\hline At $20^{\circ} \mathrm{C}$ - $\operatorname{dark}(\%)$ & 12 & 23 & 0.05 \\
\hline Normal seedlings after $\mathrm{AA}^{\mathrm{w}}(\%)$ & 97 & 99 & 0.08 \\
\hline Vigor index ${ }^{v}$ & 697 & 722 & 0.52 \\
\hline Radicle length (pixels/seedling) ${ }^{\mathrm{v}}$ & 262 & 290 & 0.21 \\
\hline
\end{tabular}

${ }^{\mathrm{z} P}$ value from analysis of variance.

${ }^{\mathrm{y}}$ Harvest index $=($ total seed dry weight per plant $) /($ plant dry weight + total seed dry weight per plant $)$.

${ }^{\mathrm{x}}$ Water productivity $=$ (total seed dry weight per plant, grams $) /($ total watering volume per plant, liters $)$.

${ }^{\mathrm{w}} \mathrm{AA}=$ accelerated aging of the seeds at $41{ }^{\circ} \mathrm{C}$ and $\approx 100 \%$ relative humidity for $72 \mathrm{~h}$.

${ }^{v}$ Values from SVIS (Seedling Vigor Image System).

water availability and plant ET were observed during seed production (Figs. 1 and 3). Consequently, lettuce plants under water deficit had a significant reduction in dry matter accumulation (Tables 1 and 2). This reduction in growth may be explained by the acclimation mechanisms activated in plants as a response to water stress, which include reduced growth of leaves, enhancement of root extension, stomata closure, and osmotic adjustment of cells (Wery, 2005). Izzeldin et al. (1980) observed similar reduced size and weight of lettuce plants grown under severe water deficit conditions (soil moisture $-0.5 \mathrm{MPa}$ ) during vegetative or reproductive growth compared with the less stressed plants.
2007), and wild bushbean (Santos et al., 2006).

In Expt. 2, plants from the dry treatment produced nearly $20 \%$ fewer seeds $(\mathrm{g})$ per plant $(P=0.051$; Table 2$)$, which was sufficient to biologically compensate for the reduction in size of dry plants and cause the wet and dry-treated lettuce plants to have similar harvest indices (Table 2). When evaluating crop management strategies in dry areas, water productivity may be more important than yield per unit area (Oweis and Hachum, 2006). The water productivity in lettuce plants from the dry treatment was $\approx 50 \%$ higher than for plants from the wet treatment. Globally, the principal areas of lettuce seed production are located in semiarid regions (Ryder, 1999), where irrigation is required. The substantial increase in water productivity attained by restricting watering represents information with the potential of being used for development of more efficient irrigation practices during lettuce seed production.

Seed weight has been positively correlated with seed vigor (Smith et al., 1973a) and seedling growth after emergence (Smith et al., 1973b). In our study, lettuce seed performance was evaluated as the ability to produce normal seedlings under optimal conditions (standard germination), to germinate at different conditions (germinability), by seedling growth and uniformity (SVIS), and by the AA test. Despite the differences in seed weight, there were no significant differences in the percentage of normal seedlings after standard germination and the germinability at different temperatures and light conditions for seeds from the different treatments in Expts. 1 and 2. Germination of 'Tango' lettuce seed was drastically reduced in the dark for treatments from Expts. 1 and 2. Although seed produced by plants under water deficit tended to have higher dark germination, light requirements were still evident and germination values in dark did not exceed 25\% (Tables 1 and 2).

The average seedling radicle length after $3 \mathrm{~d}$ of germination has been used for vigor evaluation of lettuce seeds (Smith et al., 1973a), and a good correlation of this parameter with lettuce field emergence and yield has been observed (Contreras and Barros, 2005; Smith et al., 1973b; Wurr and Fellows, 1985). The SVIS integrates parameters of seedling growth (radicle and hypocotyl) and uniformity (standard deviation from seedling lengths) to produce a vigor index from 0 (minimum vigor) to 1000 (maximum vigor) (Sako et al., 2001). In Expts. 1 and 2, the seed vigor index and average radicle length tended to be higher in seeds from plants under water deficit (Tables 1 and 2); however, significant differences were only observed for radicle length in Expt. 1. Seeds from the very dry treatment produced seedlings with significantly longer radicles than seeds from the wet and dry treatments. A similar result was reported by Izzeldin et al. (1980) who observed that 'Calmar' (crisphead type) lettuce seeds from 
plants under severe water stress were heavier and produced seedlings with longer radicle lengths than seeds from plants with moderate or no water deficit.
The AA test has been used for evaluation of seed storability and vigor (Copeland and McDonald, 2001). Treatments from Expt. 2 did not differ significantly for the AA test
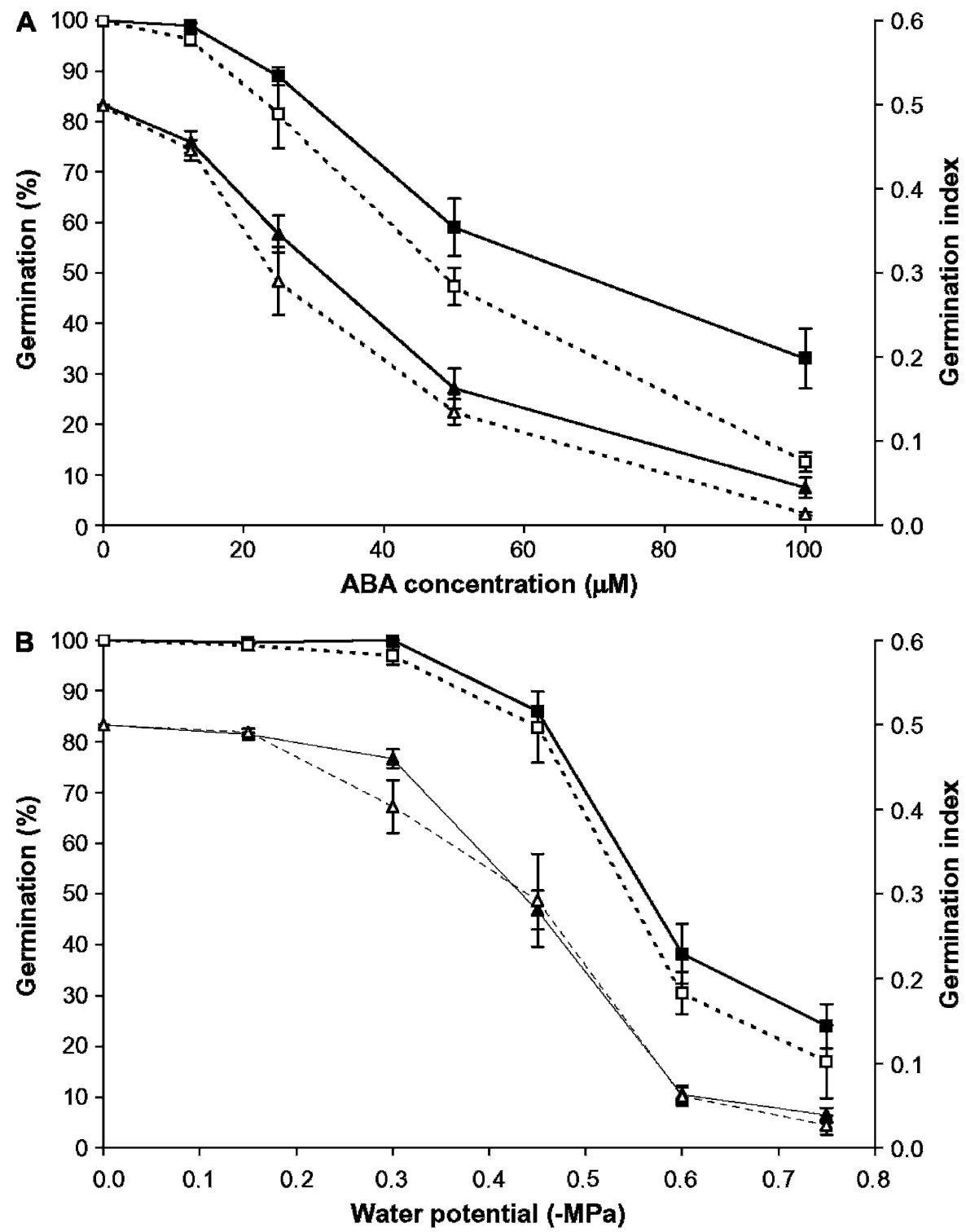

Fig. 5. Germination percentage (squares) and germination index (triangles) of lettuce seeds from wet (solid line) and dry (broken line) irrigation treatments (Expt. 2) at five abscisic acid (ABA) concentrations (A) and five water potentials (B). Data are means \pm SE of four replications of 50 seeds each.

results $(P=0.09)$, although seeds from the dry treatment performed better after the aging (Table 2). Therefore, although results from Expts. 1 and 2 support the idea that lettuce seeds produced by plants under water deficit are heavier and more vigorous (Izzeldin et al., 1980), differences in seed vigor were of little or no significance.

Seed dormancy has been positively related with $\mathrm{ABA}$ presence or sensitivity of seeds to this phytohormone (Benech-Arnold et al., 1991; Finch-Savage and LeubnerMetzger, 2006; Ni and Bradford, 1993; Yogeesha et al., 2006) and also sensitivity of germination to water potential $(\mathrm{Ni}$ and Bradford, 1993). In general, seeds from Expts. 1 and 2 performed similarly when germinated in increased exogenous ABA and decreased water potential; however, according to the small but consistent differences observed, seeds from the very dry (Expt. 1) and dry (Expt. 2) treatments tended to be more sensitive (Figs. 2 and 5). Thus, seeds from plants with restricted irrigation would be more dormant than those from wellhydrated plants. These results differed from the reported trend that associates water stress with production of less dormant seeds (Fenner, 1991; Gutterman, 2000; Hilhorst and Toorop, 1997), which could be explained by species differences or an effective acclimation of the plants to reduced availability of water before the seed production period. In Expts. 1 and 2, the differences in watering volumes started at bolting, and plants adjusted to the water available by reducing their size and producing fewer seeds per plant (Tables 1 and 2). In this way, availability of water and nutrients would not be restricted for the growing seeds during the period of seed development; in fact, seeds from the treatments with reduced water availability were able to accumulate more individual weight and tended to be more vigorous than those from the wet treatments (Tables 1 and 2).

The methodology used in Expt. 3 differed from Expts. 1 and 2 because water stress was applied abruptly to well-hydrated lettuce plants grown in growth chambers and the effects were evaluated only on seeds at 4 or 8 DAF when water was withheld. Curves of dry

Table 3. Parameters of quality for lettuce seeds produced under different water restriction treatments (Expt. 3). ${ }^{z}$

\begin{tabular}{|c|c|c|c|}
\hline \multirow[b]{2}{*}{ Parameter } & \multicolumn{3}{|c|}{ Treatment } \\
\hline & No water restriction & No watering from $8 \mathrm{DAF}^{\mathrm{y}}$ & No watering from 4 DAF \\
\hline Seed dry weight (mg/seed) & $0.782 \pm 0.005$ & $0.854 \pm 0.001$ & $0.819 \pm 0.008$ \\
\hline Normal seedlings at $20{ }^{\circ} \mathrm{C}(\%)$ & $98.6 \pm 0.5$ & $94.3 \pm 2.0$ & $94.3 \pm 1.7$ \\
\hline Germination at $20^{\circ} \mathrm{C}(\%)$ & $100.0 \pm 0.0$ & $99.5 \pm 0.5$ & $100.0 \pm 0.0$ \\
\hline Germination index at $20^{\circ} \mathrm{C}$ & $1.00 \pm 0.00$ & $0.98 \pm 0.01$ & $0.99 \pm 0.01$ \\
\hline Germination at $30^{\circ} \mathrm{C}(\%)$ & $100.0 \pm 0.0$ & $99.0 \pm 1.0$ & $98.5 \pm 1.0$ \\
\hline Germination index at $30^{\circ} \mathrm{C}$ & $1.00 \pm 0.00$ & $0.90 \pm 0.02$ & $0.90 \pm 0.02$ \\
\hline Dark germination at $20{ }^{\circ} \mathrm{C}(\%)$ & $100.0 \pm 0.00$ & $98.5 \pm 0.5$ & $99.5 \pm 0.5$ \\
\hline Dark germination at $30{ }^{\circ} \mathrm{C}(\%)$ & $88.4 \pm 3.7$ & $31.0 \pm 5.1$ & $15.0 \pm 1.3$ \\
\hline Normal seedlings after $\mathrm{AA}^{\mathrm{x}}(\%)$ & $2.0 \pm 1.2$ & $77.0 \pm 2.4$ & $49.0 \pm 6.6$ \\
\hline Germination at $20^{\circ} \mathrm{C}$ with $\mathrm{ABA}, 50 \mu \mathrm{M}(\%)$ & $97.5 \pm 1.3$ & $78.9 \pm 3.6$ & $74.8 \pm 2.6$ \\
\hline Germination at $20^{\circ} \mathrm{C}$ in $-0.4 \mathrm{MPa}$ osmotic solution (\%) & $78.3 \pm 5.0$ & $94.5 \pm 0.9$ & $91.5 \pm 2.2$ \\
\hline
\end{tabular}

${ }^{\mathrm{z}}$ Data are presented as average $\pm \mathrm{SE}$ values from four subsamples of 50 seeds each.

${ }^{\mathrm{y}} \mathrm{DAF}=$ days after flowering.

${ }^{\mathrm{x}} \mathrm{AA}=$ accelerated aging of the seeds at $41^{\circ} \mathrm{C}$ and $\approx 100 \%$ relative humidity for $72 \mathrm{~h}$.

$\mathrm{ABA}=$ abscisic acid. 
matter accumulation for developing seeds from the control plants (no water restriction) were performed (data not shown), and physiological maturity was estimated to occur 13 DAF. Therefore, 4 and 8 DAF represented approximately one-third and two-thirds of seed physiological maturity, respectively.

Dry weight tended to be higher for individual lettuce seeds from plants with water restriction, which could be explained by more flowering and competition for resources in plants without water deficit. However, seeds from lettuce plants that received the last watering 4 DAF were smaller than those that received the last watering $8 \mathrm{DAF}$, which could be the result of less resources being available for filling seeds at the earlier water deficit.

Standard seed germination from the treatments without watering from 8 and 4 DAF produced $94 \%$ normal seedlings, which was lower than the control, which had 99\% normal seedlings (Table 3). This difference in germination results may be interpreted as a reduction in seed quality resulting from the applied water stress. The control also outperformed the water stress treatments in GI at $30{ }^{\circ} \mathrm{C}$, dark germination percentage at $30^{\circ} \mathrm{C}$, and germination percentage at $50 \mu \mathrm{M} \mathrm{ABA}$ (Table 3). These results suggest a reduction in seed germinability as a consequence of reduced water availability to the mother plant during seed development. However, seed germinability (percentage and rate) at -0.4 $\mathrm{MPa}$ water potential was better for seeds from the water deficit treatments than for seeds from the control. These results showed that germination sensitivity to external ABA and negative water potential are not necessarily correlated and both aspects should be tested when specific germinability aspects of a seed lot need to be evaluated.

Light requirement for lettuce seed germination has been reported and extensively studied (Ikuma and Thimann, 1964; McArthur, 1978; Toyomasu et al., 1998; van der Woude and Toole, 1980). The degree of light sensitiveness in lettuce varies among cultivars and 'Tango' is described as a very photosensitive genotype (H.J. Hill, Seed Dynamics, per. comm.). In fact, in Expts. 1 and 2 lettuce seeds did not germinate more than $25 \%$ in the dark (Tables 1 and 2). However, in Expt. 3, dark germination at $20{ }^{\circ} \mathrm{C}$ was close to $100 \%$ for seed from all the treatments (Table 3). Seed production in Expt. 3 was performed in growth chambers with artificial fluorescent light, which has a red to far-red (R:FR) ratio over 6 , which is much higher than the natural light used in the greenhouse during seed production in Expts. 1 and 2 (R:FR ratio between 0.9 and 1.2) (Contreras, 2007). Dark germination of mouseear cress [Arabidopsis thaliana (L.) Heynh.] seeds varied depending on light quality during seed production, and seed developed under light with a high R:FR ratio germinated better in the dark (Hayes and Klein, 1974). We have observed a similar result with 'Tango' lettuce seeds (Contreras, 2007), and the greater dark germination of seeds in this experiment can be explained by the modified light quality inside the growth chambers compared with the greenhouse seed production environment.

Interestingly, results from the AA test showed that lettuce seeds from the water stress treatments performed better than seeds from the control (Table 3). In other experiments, we have observed that the AA test works as a good predictor for storability of 'Tango' lettuce seed (Contreras, 2007), which suggests that seeds from water stress treatments had better storability. Similar results have been reported for seeds of peanut (Ramamoorthy and Basu, 1996) and rapidcycling brassica (Sinniah et al., 1998), in which seed produced under water stress had better storability than seed from wellhydrated controls. From an ecological point of view, producing seed with better longevity under conditions of stress could ensure survival of the seeds in the soil for prolonged periods of time until more favorable emergence conditions are present.

In summary, the effects of restricted water availability during lettuce seed development depended on how the water deficit was imposed. When the volume of water available to the plants was reduced before flowering, plants produced fewer but heavier seeds. The increase in individual seed weight was accompanied by improvements in seed vigor (assessed by seedling growth and AA) of little or no significance. Additionally, an important increase in water productivity (lettuce seed yield per volume of water applied) can be attained by restricting watering volumes. Lettuce plants under water deficit were more compact and produced fewer seeds per plant, suggesting that field plant populations should be increased when restricted watering occurs. The potential and feasibility of applying this information for improving irrigation management in lettuce seed production requires evaluation in field experiments and may depend on the conditions of particular seed production areas and producers.

When water stress was applied abruptly to lettuce plants with seeds in the early stages of development, germinability was negatively affected. Total and sudden withholding of watering to lettuce plants during seed production should be avoided because of the potential reduction in quality that can affect individual seeds.

\section{Literature Cited}

Bartels, M. and K. Caesar. 1987. The influence of drought stress in various growth phases on growth, flower drop and yield of soyabeans Glycine max. (L.) Merr. J. Agron. Crop Sci. 158:346-352.

Benech-Arnold, R.L., M. Fenner, and P.J. Edwards. 1991. Changes in germinability, ABA content and ABA embryonic sensitivity in developing seeds of Sorghum bicolor (L.) Moench. induced by water stress during grain filling. New Phytol. 118:339-347.

Castañeda Saucedo, M.C., L. Córdova Téllez, V.A. González Hernández, A. Delgado Alvarado, A. Santacruz Varela, and G. García de los Santos. 2006. Respuestas fisiológicas, rendimiento y calidad de semilla en fríjol sometido a estrés hídrico. Interciencia 31:461-466.

Champolivier, L. and A. Merrien. 1996. Effects of water stress applied at different growth stages to Brassica napus L. var. oleifera on yield, yield components and seed quality. Eur. J. Agron. 5:153-160.

Contreras, S. 2007. Effects of maternal plant environment on lettuce (Lactuca sativa L.) seed dormancy, germinability, and storability. Ohio State Univ., Columbus, PhD Diss.

Contreras, S. and M. Barros. 2005. Pruebas de vigor en semillas de lechuga y su correlación con emergencia. Cienc. Invest. Agraria 32:3-11.

Copeland, L.O. and M.B. McDonald. 2001. Principles of seed science and technology. Kluwer Academic Publishers, Boston, MA.

Fenner, M. 1991. The effects of the parent environment on seed germinability. Seed Sci. Res. $1: 75-84$.

Finch-Savage, W.E. and G. Leubner-Metzger. 2006. Seed dormancy and the control of germination. New Phytol. 171:501-523.

Fougereux, J.A., T. Doré, F. Ladonne, and A. Fleury. 1997. Water stress during reproductive stages affects seed quality and yield of pea (Pisum sativum L.). Crop Sci. 37:1247-1252.

George, R.A.T. 1999. Vegetable seed production. CABI Pub., Wallingford, Oxon, UK.

Ghassemi-Golezani, K., A. Soltani, and A. Atashi. 1997. The effect of water limitation in the field on seed quality of maize and sorghum. Seed Sci. Technol. 25:321-323.

Gutterman, Y. 2000. Maternal effects on seeds during development, p. 59-84. In: Fenner, M. (ed.). Seeds: The ecology of regeneration in plant communities. 2nd ed. CABI Publishing, Wallingford, UK.

Hayes, R.G. and W.H. Klein. 1974. Spectral quality influence of light during development of Arabidopsis thaliana plants in regulating seed germination. Plant Cell Physiol. 15:643653.

Hilhorst, H.W.M. and P.E. Toorop. 1997. Review on dormancy, germinability, and germination in crop and weed seeds. Adv. Agron. 61:111165 .

Ikuma, H. and K.V. Thimann. 1964. Analysis of germination processes of lettuce seed by means of temperature and anaerobiosis. Plant Physiol. 39:756-767.

International Seed Testing Association. 1999. International rules for seed testing. Seed Sci. Technol. 27:Supplement.

Izzeldin, H., L.F. Lippert, and F.H. Takatori. 1980. An influence of water stress at different growth stages on yield and quality of lettuce seed. J. Amer. Soc. Hort. Sci. 105:68-71.

Ludlow, M.M., J.M. Santamaria, and S. Fukai. 1990. Contribution of osmotic adjustment to grain yield in Sorghum bicolor (L.) Moench under water-limited conditions: II. Water stress after anthesis. Aust. J. Agr. Res. 41:67-78.

Maguire, J.D. 1962. Speed of germination- aid in the selection and evaluation for seedling emergence and vigor. Crop Sci. 2:176-177.

McArthur, J.A. 1978. Light effects upon dry lettuce seeds. Planta 144:1-5.

Michel, B.E. 1983. Evaluation of the water potentials of solutions of polyethylene glycol 8000 both in the absence and presence of other solutes. Plant Physiol. 72:66-70.

Ni, B.R. and K.J. Bradford. 1993. Germination and dormancy of abscisic acid- and gibberellindeficient mutant tomato (Lycopersicon esculentum) seeds: Sensitivity of germination to abscisic acid, gibberellin, and water potential. Plant Physiol. 101:607-617. 
Oliva, R.N., J.J. Steiner, and W.C. Young, III. 1994. Red clover seed production: II. Plant water status on yield and yield components. Crop Sci. 34:184-192.

Oweis, T. and A. Hachum. 2006. Water harvesting and supplemental irrigation for improved water productivity of dry farming systems in West Asia and North Africa. Agr. Water Manage. 80:57-73.

Pieta-Filho, C. and R.H. Ellis. 1991. The development of seed quality in spring barley in four environments: I. Germination and longevity. Seed Sci. Res. 1:163-177.

Ramamoorthy, K. and R.N. Basu. 1996. Studies on the effect of moisture stress at different growth phases on seed vigour, viability and storability in peanut (Arachis hypogaea L.). J. Agron. Crop Sci. 177:33-37.

Ryder, E.J. 1999. Lettuce, endive, and chicory. CABI Publishing, Wallingford, UK.

Sako, Y., M.B. McDonald, K. Fujimura, A.F. Evans, and M.A. Bennett. 2001. A system for automated seed vigour assessment. Seed Sci. Technol. 29:625-636.

Santos, A.M.D., L.M.G. Rosa, L.B. Franke, and C. Nabinger. 2006. Heliotropism and water availability effects on flowering dynamics and seed production in Macroptilium lathyroides. Rev. Bras. Sementes 28: 45-52.
Shock, C.C., E.B.G. Feibert, L.D. Saunder, and J. Klauzer. 2007. Deficit irrigation for optimum alfalfa seed yield and quality. Agron. J. 99:992-998.

Sinniah, U.R., R.H. Ellis, and P. John. 1998. Irrigation and seed quality development in rapid-cycling brassica: Seed germination and longevity. Ann. Bot. (Lond.) 82:309-314.

Smith, O.E., N.C. Welch, and T.M. Little. 1973a. Studies on lettuce seed quality, I. Effect of seed size and weight on vigor. J. Amer. Soc. Hort. Sci. 98:529-533.

Smith, O.E., N.C. Welch, and O.D. McCoy. 1973b. Studies on lettuce seed quality: II. Relationship of seed vigor to emergence, seedling weight, and yield. J. Amer. Soc. Hort. Sci. 98:552-556.

Soffer, H. and O.E. Smith. 1974. Studies on lettuce seed quality: III. Relationships between flowering pattern, seed yield, and seed quality. J. Amer. Soc. Hort. Sci. 99:114-117.

Toyomasu, T., H. Kawaide, W. Mitsuhashi, Y. Inoue, and Y. Kamiya. 1998. Phytochrome regulates gibberellin biosynthesis during germination of photoblastic lettuce seeds. Plant Physiol. 118:1517-1523.

U.S. Department of Agriculture. 2007. Vegetables and Melons Outlook/VGS-321/21 June 2007. Economic Research Service. 18 July 2007 $<$ http://www.ers.usda.gov/publications/vgs/ tables/fresh.pdf $>$. van der Woude, W.J. and V.K. Toole. 1980 Studies of the mechanism of enhancement of phytochrome-dependent lettuce seed germination by prechilling. Plant Physiol. 66:220 224.

Wery, J. 2005. Differential effects of soil water deficit on the basic plant functions and their significance to analyze crop responses to water deficit in indeterminate plants. Aust. J. Agr. Res. 56:1201-1209.

Wurr, D.C.E. and J.R. Fellows. 1985. A determination of the seed vigour and field performance of crisp lettuce seedstocks. Seed Sci. Technol. 13:11-17.

Yogeesha, H.S., K.K. Upreti, K. Padmini, K. Bhanuprakash, and G.S.R. Murti. 2006. Mechanism of seed dormancy in eggplant (Solanum melongena L.). Seed Sci. Technol. 34:319 325.

Žebrauskienè, A., L. Kmitienè, Č. Bobinas, P. Duchovskis, and A. Kmitas. 2005. Influence of soil moisture deficit in various phases of edible onion development on seed yield and quality. Sodininkystė Ir Daržininkystė 24:261272.

Zhao, D.L., Y.Z. Xu, Y.F. Huang, and X. Xu. 1993. The effects of water deficiency on the development of cotton seeds during flowering and fruiting stages. Acta Agron. Sinica 19:546552. 